\title{
Determination of lipid content in fish samples from bioaccumulation studies: contributions to the revision of guideline OECD 305
}

\author{
Christian Schlechtriem*, Annette Fliedner and Christoph Schäfers
}

\begin{abstract}
Background: The bioaccumulation potential of chemical substances is commonly determined in flow-through fish tests according to the Organization for Economic Cooperation and Development (OECD) technical guideline (TG) 305, aiming at the determination of bioconcentration factors (BCF). Investigations on aquatic organisms have shown a significant positive correlation between the accumulation of a chemical and the lipid content of organisms. Residue levels can thus differ between individuals, species, and size groups depending on their lipid content. BCF values can be normalized by lipid content; however, this requires the use of appropriate extraction techniques to ensure the complete extraction of total lipids from fish/tissue samples. The OECD TG 305 is currently under revision. A literature review was carried out to select preferred methods which shall be included in the updated OECD TG 305 along with a sampling schedule for lipid measurement in fish.

Results: An overview and appraisal of a broad range of lipid extraction methods is presented. Extraction procedures applied in bioaccumulation studies described in the literature and procedures currently used for such studies by governmental, academic, and industrial labs are surveyed. Possible impacts of unsuitable extraction techniques on lipid normalized BCF results were assessed. Default values for BCF normalization commonly used in bioaccumulation studies are described. The effect of differences in residue distribution over different organs and/or lipids on the normalization of BCF values is discussed.

Conclusions: A broad range of procedures for lipid extraction are available. However, only the use of suitable extraction techniques guarantees the complete extraction of total lipids from fish samples in bioaccumulation studies which is required to ensure the correct lipid normalization of BCF values. Preferred methods for inclusion in the updated OECD 305 test guideline as well as a standard schedule for lipid measurements are suggested.
\end{abstract}

Keywords: Lipid extraction procedures, Standard methods, BCF, Lipid normalization, Tissue distribution

\section{Background}

Bioaccumulation of chemical substances can be caused by bioconcentration, mainly via respiratory membranes, or by biomagnifications via dietary uptake. As partitioning between water or food and outer membranes of organisms represents the most important process of bioaccumulation, it is of particular interest when dealing with substances with certain physicochemical properties, e.g., lipophilicity and persistence. In aquatic systems, sediments, and soils, these substances tend to

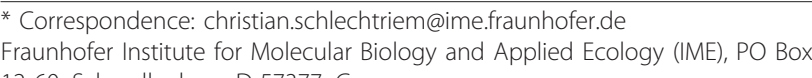

* Correspondence: christian.schlechtriem@ime.fraunhofer.de
Fraunhofer Institute for Molecular Biology and Applied Ecology (IME), PO Box 12 60, Schmallenberg D-57377, Germany
}

勿

(C) 2012 Schlechtriem et al; licensee Springer. This is an Open Access article distributed under the terms of the Creative Commons Attribution License (http://creativecommons.org/licenses/by/2.0), which permits unrestricted use, distribution, and reproduction in any medium, provided the original work is properly cited.

concentrate mainly in the lipid fraction of organisms and may lead to substantial physiological burdens. The accumulation of such residues in the food chain can reach levels toxic to predators and represents a risk for human health. Assessing the bioconcentration as well as the biomagnification potential is therefore an important issue for the environmental and human risk assessment of chemicals and one of the main features in environmental monitoring.

The Organization for Economic Cooperation and Development (OECD) technical guideline (TG) 305 [1] focuses on the process of bioconcentration and aims at the determination of the bioconcentration factor (BCF), 
a proportionality constant relating the concentration of a chemical in an organism to its concentration in the ambient water at the steady state between uptake and depuration. Investigations in the aquatic environment have revealed a significant positive correlation between the accumulation of a chemical and the lipid content of organisms, and residue levels thus differ between individuals, species, and size groups depending on their lipid contents [2-4]. Therefore, variations in these data can be reduced when $\mathrm{BCF}$ values are normalized by lipid content $[5,6]$. Furthermore, this facilitates the extrapolation between species and sites.

However, it must be kept in mind that lipids are not a uniform compartment and that different lipid classes, e. g., the relatively polar phospholipids common in cell membranes, the nonpolar triacylglycerols in storage lipids, the neutral steroids, glycolipids, triglycerids, and free fatty acids, have quite different properties. Partitioning of lipophilic substances in the total lipid fraction is most probably related to these differences in polarity $[7,8]$.

Polarity also governs lipid solubility in water and organic solvents and, thus, the extraction of total lipids. Lipid fractions are usually characterized by different ratios of polar and nonpolar lipids, mainly depending on the total lipid content of the animals/tissues. The use of appropriate extraction techniques based on solvent systems with the right polarity is thus essential $[8,9]$. In addition, other factors, e.g., temperature, $\mathrm{pH}$, light, and oxygen, may influence lipid extractions [5]. In view of these considerations, it is not surprising that up to now, many different extraction methods have been proposed, but no standard method suitable for all tissues/species has been agreed upon.

Bioconcentration guidelines such as OECD TG 305 [1], the United States Environmental Protection Agency Office of Pollution Prevention and Toxics (U.S. EPA OPPTS) 850.1730, [10] and Japanese Industrial Standards [11] emphasize the importance of lipid normalization; however, a clear guidance on lipid measurement in fish is missing. The results obtained with different extraction methods may differ quite considerably $[6,8,9,12-18]$, leading to over- or underestimations when normalizing BCF values to lipid contents. Therefore, the selection of appropriate extraction techniques using mixed systems of nonpolar and polar solvents is required to ensure the complete extraction of total lipids from fish/tissue samples. In this context, the OECD 305 guideline [1] recommends the use of chloroform/methanol for determination of fish lipid content. The microgravimetric assay for total lipids described by Gardner et al. [19] is given as a key reference. However, a broad range of analytical procedures are available which can be used for lipid measurements as part of bioconcentration studies and thus may have a potential impact on the results obtained. To guarantee the comparability of BCFs obtained in different studies, the analytical procedures should be further standardized. Therefore, in the course of revising OECD guideline 305 [1], lipid determination is one point that needs clarification.

The aim of the present survey was to review current literature to give an overview over lipid extraction methods used in bioaccumulation studies and to appraise each method with respect to strengths and weaknesses in terms of reproducibility, ease of conductance, and robustness. Effects induced by the use of inappropriate lipid measurement methods on the result of lipid normalization are described. Lipid extraction protocols recommended to be included in the updated OECD TG 305 along with a sampling schedule of lipid measurement in fish are provided.

\section{Main text and discussion}

\section{Overview and appraisal of lipid extraction methods}

The review of methods for lipid extraction and an appraisal of each method are presented in Additional file 1 . The focus of this survey is on traditional extraction procedures using organic solvents (e.g., [20-22] or the Soxhlet method [23]); however, also nondestructive instrumental methods based on near-infrared (NIR) spectroscopy or nuclear magnetic resonance (NMR) spectroscopy are presented. Each method currently employed for the determination of lipid content has its advantages and disadvantages, and there is no procedure available which is suitable for all types of lipids.

For choosing suitable methods for preparation of lipid extracts from fish tissues based on solvent extraction, different criteria must be considered. The simplicity and efficiency of the method are of central interest. However, the choice of method used for the determination of lipid content will be dictated to a large extent by the cost and by the urgency with which the results are required. The nondestructive instrumental methods are for instance exceptionally quick and involve very little sample preparation, but expensive and sophisticated equipment is required which might not be widely available. In addition, their degree of accuracy is perhaps less than that of the destructive solvent extraction methods. Finally, the toxicity of the solvents for humans (i.e., lab technicians) and the ease of disposal of the used solvents should be a prime consideration.

The amount of fish biomass sampled during bioaccumulation studies is usually limited due to the small size and low number of animals. Some procedures for solvent extraction might be principally suitable for extraction of lipids from fish tissues, but relatively large sample volumes are required (e.g., [20]). In these cases, 
a careful adjustment of the extraction procedure to reduced sample sizes is required. Several microgravimetric assays have been described (e.g., $[19,24])$. The relative merits of the different methods have to be considered when a preferred method for inclusion in the updated OECD 305 test guideline is selected.

\section{Lipid determination in bioaccumulation studies}

The vast majority of bioaccumulation data available in the literature have been obtained in the context of environmental monitoring or field studies. Residue levels are usually expressed on wet weight basis or normalized to lipid weight.

Publications of bioconcentration studies according to OECD TG 305 [1] or U.S. EPA OPPTS 850.1730 [10] are rare: Schettgen [25] performed OECD TG 305 studies with Triclosan and some pyrethroid pesticides. Total lipids were determined according to Hara and Radin [22] using a two step extraction with hexane and isopropanol followed by the photometrical determination of the lipid-sulphosphovanillin complex after digestion with sulphuric acid [26]. Fox et al. [27] performed bioconcentration tests on polychlorinated biphenyls (PCBs) according to OECD TG 305, but no details on the methods used for lipid extraction except the solvent combination (hexane/2-propanol) are presented. Yakata et al. [28] studied the influence of dispersants on the $\mathrm{BCF}$ of seven organic compounds in flow-through test systems according to OECD TG 305. Lipids were determined using the Bligh and Dyer [21] method.

Other papers report on bioconcentration tests according to OECD TG 305 [1] or U.S. EPA OPPTS 850.1730 [10] without lipid determination being carried out (e.g., [29-32]). The outcome of the literature review with respect to guideline studies and lipid determination methods was thus not satisfactory due to a shortage of data. This is probably due to the fact that the majority of bioconcentration studies according to guidelines are performed in the context of regulatory risk assessment of chemicals. These studies have to be performed according to GLP (Good Laboratory Practice) and are thus of high quality. However, they are strictly confidential and not available to the public and could thus not be reviewed for this report. The literature review was therefore amended by short interviews with laboratories that perform OECD 305 studies in the context of registration and notification.

Eight international laboratories involved in bioaccumulation studies were asked for information about their standard operation procedures used for lipid extraction from fish tissues. Our survey showed that despite the broad range of methods available for lipid extraction, only a small group of techniques is routinely applied in bioaccumulation studies. Five of the eight laboratories interviewed stated that they commonly use solvent extraction methods based on chloroform/methanol according to Bligh and Dyer [21] or Randall et al. [9] which is a modification of the procedure originally described by Folch et al. [20]. Two laboratories commonly use the Smedes method [14] which is based on non-chlorinated solvents. Only one lab mentioned to use a nondestructive instrumental method based on NIR. The results show that most labs follow the current guidelines of OECD 305 [1] where the use of chloroform/methanol extraction techniques is recommended for analysis of fish samples. The Smedes method [14] was developed for the determination of total lipid in fish and extensively compared with the Bligh and Dyer method [21] for different fish and shellfish samples. The results were in agreement with the extraction following Bligh and Dyer [33,34] using chlorinated solvents, and the method is now part of the QUASIMEME Laboratory Performance Studies [35] as a 'low-toxic' method for the determination of total lipid in marine biota. It can be assumed that the results of all seven labs which use solvent extraction procedures for analysis of fish samples are comparable. Also, the values obtained by NIR are most likely in agreement with those obtained by solvent extraction, as described by Darwish et al. [36] and Mathias et al. [37].

In conclusion, the results of our survey indicate that analytical methods commonly applied by governmental, academic, and industrial labs for the determination of lipid content in fish sampled from bioaccumulation studies are of high quality. The estimation of possible impacts of unsuitable extraction techniques on lipidnormalized $\mathrm{BCF}$ results might therefore be a rather theoretical issue.

\section{Effect of lipid extraction procedures on lipid-based BCF values}

Principally, extraction differences may lead to substantial differences in comparing BCFs across studies and among species of varying lipid composition [9]. However, a critical investigation of different methods for lipid determination with respect to their impact on estimated BCFs is missing. Due to the limited amount of published results from bioaccumulation studies which were carried out according to OECD TG 305 [1], the specific comparison of BCFs estimated for single contaminants is difficult. Geyer et al. [38] described the relationship between the lipid content of fish and their bioconcentration potential of 1,2,4-trichlorobenzene. This study presents a valuable collection of references of older bioaccumulation studies. For instance, in a study on rainbow trout (Oncorhynchus mykiss), presented by Galassi and Calamari [39], a lipid content of $3.2 \%$ was estimated for the newly hatched animals 
leading to a wet weight-based BCF $\left(\mathrm{BCF}_{\mathrm{W}}\right)$ of 349 (based on lipid weight, the respective lipid-based $\mathrm{BCF}$ $\left(B C F_{L}\right)$ was 10,906$)$. In a further study on the same species but with bigger animals, a lipid content of $8.3 \%$ was determined leading to a $\mathrm{BCF}_{\mathrm{W}}$ of $1,300\left(\mathrm{BCF}_{\mathrm{L}}=\right.$ 15,660) [40]. Lipid contents in both studies were determined by the Soxhlet extraction [23]. However, different solvent systems ( $n$-hexane vs. acetone/hexane) and different boiling periods ( $8 \mathrm{~h}$ vs. $24 \mathrm{~h}$ ) were applied. It can be assumed that in the first study, due to the neutral solvent ( $n$-hexane), only the neutral lipids were removed leading to a lower lipid content and thus a higher $\mathrm{BCF}_{\mathrm{L}}$ value. In contrast, the lipid content presented in the second study seems to be exceptionally high for animals of the given size.

\section{Whole body lipid content default values for lipid normalization of BCF}

Fish lipid content varies according to species, age, sex, season, and location, and it can range from around $0.5 \%$ to $20 \% w / w$ or more in the wild (e.g., [38]). BCF values for lipophilic compounds estimated on a wet weight basis $\left(\mathrm{BCF}_{\mathrm{W}}\right)$ increase with increasing lipid contents. Normalization of BCF values to lipid content is one way to reduce variability when comparing measured $\mathrm{BCF}$ values, for instance, for different species or animals of different life stages. Lipid contents are commonly used to calculate $\mathrm{BCF}$ values on a percent lipid basis $\left(\mathrm{BCF}_{\mathrm{L}}\right)$ but can be further used to calculate a normalized whole body BCF assuming a fixed whole body lipid content. A default value of $5 \%$ is most commonly used as this represents the average lipid content of the small fish used in OECD TG 305 [1] including the rainbow trout (O. mykiss), bluegill sunfish (Lepomis macrochirus), zebrafish (Danio rerio), fathead minnow (Pimephales promelas), and common carp (Cyprinus carpio) $([41,42]$ cited in the REACH TGD (R.7.10.4) [43]).

No default value is defined in OECD TG 305 [1], and a percent normalization was thus not performed in the published bioaccumulation studies following this guideline $[25,28]$.

Fish lipid contents should be always measured and reported together with the calculated BCF values. The interviews revealed that fish lipid contents are usually measured and reported but that BCFs are not necessarily further normalized on a lipid basis. Only one lab mentioned that BCF values are normalized to a default value of $6 \%$ which represents the average lipid content of the bluegill sunfish (L. macrochirus) used in their bioaccumulation studies. A common default value (e.g., $5 \%$, as described above) should be defined in the revised OECD guideline to give a clear basis for the comparison of BCF values across studies and among species.

\section{Differences in residue distribution over different organs and/or lipids}

Bioconcentration factors for lipophilic compounds estimated on a wet weight basis $\left(\mathrm{BCF}_{\mathrm{W}}\right)$ increase with increasing lipid content. The generally held view is that neutral storage and membrane lipids are the most important classes for the bioaccumulation of nonpolar and polar residues, respectively. Therefore, apart from the lipid content, also the lipid composition might have an effect on the bioaccumulation potential of an animal. However, with respect to differences in residue distribution over different lipid types, only little data are available. Chefurka and Gnidec [44] found that dichlordiphenyltrichlorethane binds to the relatively polar membrane lipids. Chlorobiphenyls were detected in both the membrane-bound and the unbound lipid fraction in fish [12]. For extractable PCBs, Randall et al. [8] reported about one third to be associated with membrane-bound lipids, whereas two thirds was found in the neutral lipid fraction. Roche et al. [45] found infrequent positive correlations between lipid contents in tissues and contaminant levels: In eel (Anguilla anguilla), muscular $\gamma$-hexachlorcyclohexane (Lindan, $\gamma \mathrm{HCH}$ ) correlated with neutral lipids. In crucian carp (Carassius carassius), muscular $\gamma \mathrm{HCH}$ correlated with total lipids and hepatic $\Sigma \mathrm{PCB}$ with phospholipids. In catfish liver (Ictalurus nebulosus), a positive correlation was detected between $\gamma \mathrm{HCH}$ and total, as well as neutral, lipids. Generally, the evidence for the role of lipid composition on differences in bioaccumulation potential is missing, and the estimation of BCF values should be better related to total lipid content than to any one fraction.

Lipid concentrations in different organs, namely, filet and liver, can vary leading to differences in residue distribution. For instance, Wu et al. [46] reported that polychlorinated dibenzodioxines and furanes accumulate mainly in the liver and that muscle concentrations correlate with liver concentrations. Variability in muscle concentrations between fish species decreased when concentrations were normalized to lipid content. Several studies describe the residue distribution over different organs (e.g., [31,45,47-53]). However, bioconcentration studies according to OECD 305 [1] are performed to obtain BCF values which - per definitionem - refer to the whole fish, and differences in residue distribution over different organs are thus not essential.

\section{Recommended method for inclusion in the updated OECD 305 test guideline}

As stated above, the selection of a suitable lipid determination method should consider the methods' reproducibility, robustness, and ease of use. Furthermore, it should not be too expensive and - ideally - work without toxic solvents. Another crucial point is the 
applicability to small quantities of samples. Many of the methods listed above were established for samples of 1 to $10 \mathrm{~g}$ and have to be modified when working with sample sizes of $<1 \mathrm{~g}$. The chloroform/methanol extraction technique recommended as standard method is well established and accepted. After the Soxhlet method [23], which is considered unsuitable for lipid extraction of fish tissues because of its dependency on conditions which are difficult to control (i.e., no precise determination of extraction cycles due to continuous flow), the Bligh and Dyer method [21] is probably the second most common lipid extraction procedure reported in the scientific literature. Due to the simultaneous use of the nonpolar chloroform and the polar methanol as solvents, this technique is characterized by high extraction efficiency. The lipid obtained can be subjected to further analysis if required. However, the major drawback of this method is the use of highly toxic solvents. We therefore suggest that the Smedes method [14] should be recommended as an alternative technique for the Bligh and Dyer procedure [21]. The Smedes method is characterized by a comparable efficiency of extraction, high accuracy, the use of less toxic organic solvents, and ease of performance. Cyclohexane has a lower density than chloroform and therefore separates at the top of the extraction mixture. Particulate matter which is centrifuged to the bottom of the jar is automatically removed from organic phase. Therefore, no filtration is necessary to remove it as with Bligh and Dyer [21] where tissue residues form on top of the lower chloroform phase. Both techniques are described in detail in Additional file 2. An alternative method for the quantitative extraction of lipids from fish using non-halogenated solvents was described by Jensen et al. [6]. Lipid recoveries comparable to the Bligh and Dyer method were obtained for cod muscle, showing the high potential of this method. However, further validation/calibration approaches as well as an interlaboratory study involving this method are required.

Due to the specific extraction procedures required for the analysis of many test substances, the use of techniques based on NIR or NMR spectroscopy (e.g., CEM Smart trac ${ }^{\mathrm{TM}}$, CEM Corporation, Matthews, NC, USA) has high potential for the lipid determination in fish sampled from bioaccumulation studies. However, the lack of intercalibration studies and the limited availability and high cost of equipment are currently the major bottleneck for the use of these techniques.

\section{Standardized sampling schedule for lipid measurement}

The OECD 305 guideline [1] states that, if possible, lipid determination and residue analysis should be performed using the same sample. However, analysis of test substances often requires specific extraction procedures which might be in contradiction to the guidelines for gravimetric lipid determination by solvent extraction. In this case (until suitable nondestructive instrumental methods are available), it is recommended to determine the fish lipid content by solvent extraction on independent fish sampled at the start and at the end of the experiment. The amount of fish per tank should be adjusted accordingly. The analysis of fish from the test and control groups at the end of the experiment is important to confirm the equal lipid content of test and control animals. As described in the OECD 305 guideline [1], the lipid content of the fish (as milligrams per kilogram wet weight) at the end of the experiment should not differ from that at the start by more $\pm 25 \%$.

\section{Conclusions}

A broad range of procedures for lipid extraction are available. However, only the use of suitable extraction techniques guarantees the complete extraction of total lipids from fish samples in bioaccumulation studies which is required to ensure the correct lipid normalization of BCF values.

\section{Additional material}

Additional file 1: Overview and appraisal of lipid extraction

methods. A table showing a review of methods for lipid extraction and an appraisal of each method.

Additional file 2: Extraction and measurement of total lipids in fish.

A document describing two techniques for the extraction and

measurement of total lipids in fish.

\section{Abbreviations}

BCF: Bioconcentration factor; $B C F_{W}$ : Wet weight-based $B C F ; B C F_{L}$ : Lipid-based BCF; OECD: Organization for Economic Cooperation and Development; TG: Technical guideline; NMR: Nuclear magnetic resonance spectroscopy; NIR: Near-infrared spectroscopy; PCB: Polychlorinated biphenyls; $\gamma \mathrm{HCH}: \gamma^{-}$ hexachlorcyclohexane.

\section{Acknowledgements}

This paper is based on the result of the literature survey 'Lipid measurement: Contributions to the revision of TG OECD 305' funded by OECD under contract for intellectual services JA00052497. The authors would like to thank the national coordinators and members of the OECD expert group supporting the current revision of this guideline for providing valuable comments on the OECD report.

\section{Authors' contributions}

CSr participated in the literature search and drafted the manuscript. AF has made a substantial contribution to the literature search. CSf has been involved in revising the manuscript critically. All authors read and approved the final manuscript.

\section{Competing interests}

The authors declare that they have no competing interests.

Received: 17 January 2012 Accepted: 3 April 2012

Published: 3 April 2012 


\section{References}

1. OECD 305: OECD Guidelines for Testing Chemicals: Proposal for Updating Guideline 305. Bioconcentration: Flow-Through Fish Test Paris 1996.

2. Baron MG: Bioconcentration. Environ Sci Technol 1990, 24:1612-1618.

3. LeBlanc GA: Trophic-level differences in bioconcentration of chemicals: implications in assessing environmental biomagnifications. Environ Sci Technol 1995, 29:154-160.

4. Stow CA, Jackson LJ, Amrhein JF: An examination of the PCB: lipid relationship among individual fish. Can J Fish Aquat Sci 1997, 54:1031-1038

5. U.S. Environmental Protection Agency EPA: In Methodology for Deriving Ambient Water Quality Criteria for the Protection of Human Health: Technical Support Document. Volume 2. Washington, D.C: Development of National Bioaccumulation Factors; 2003.

6. Jensen S, Häggberg L, Jörundsdóttir H, Odham G: A quantitative lipid extraction method for residue analysis of fish involving nonhalogenated solvents. J Agric Food Chem 2003, 51:5607-5611.

7. Ewald G, Larsson P: Partitioning of ${ }^{14} \mathrm{C}$-labelled 2,2',4,4'tetrachlorobiphenyl between water and fish lipids. Environ Toxicol Chem 1994, 13(10):1577-1580.

8. Randall RC, Young DR, Lee H II, Echols SF: Lipid methodology and pollutant normalization relationships for neutral nonpolar organic pollutants. Environ Toxicol Chem 1998, 17(5):788-791.

9. Randall RC, Lee V II, Ozretich RJ, Lake JL, Pruell RJ: Evaluation of selected lipid methods for normalizing pollutant bioaccumulation. Environ Toxicol Chem 1991, 10(11):1431-1436.

10. U.S. Environmental Protection Agency EPA: Ecological effects test quidelines OPPTS 850.1730 Fish BCF Washington DC 1996.

11. Japanese Industrial Standards JIS: Concentration test of chemical substances in fish [http://www.meti.go.jp/english/information/data/TESTfish.html].

12. De Boer J: Chlorobiphenyls in bound and non-bound lipids of fishes; comparison of different extraction methods. Chemosphere 1988, 17(9):1803.

13. Ewald G, Bremle G, Karlsson A: Differences between Bligh and Dyer and Soxhlet extraction of PCBs and lipids from fat and lean fish muscle: implications for data evaluation. Mar Poll Bull 1998, 36(3):222-230.

14. Smedes F: Determination of total lipid using non-chlorinated solvents. Analyst 1999, 124:1711-1718.

15. Iverson SJ, Lang SLC, Cooper MH: Comparison of the Bligh and Dyer and Folch methods for total lipid determination in a broad range of marine tissues. Lipids 2001, 36(11):1283-1287

16. Zhuang W, McKague B, Reeve D, Carrey J: A comparative evaluation of accelerated solvent extraction and polytron extraction for quantification of lipids and extractable organochlorine in fish. Chemosphere 2004, 54:467-480.

17. Inouye LS, Lotufo GR: Comparison of macro-gravimetric and microcolorimetric lipid determination methods. Talanta 2006, 70(3):584-587.

18. Lu Y, Ludsin SA, Fanslow DL, Pothoven SA: Comparison of three microquantity techniques for measuring total lipids in fish. Can J Fish Aquat Sci 2008, 65:2233-2241.

19. Gardner WS, Frez WA, Cichocki EA, Parrish CC: Micromethod for lipids in aquatic invertebrates. Limnol Oceanogr 1985, 30(5):1099-1105.

20. Folch J, Lees M, Sloane-Stanley GH: A simple method for the isolation and purification of total lipides from animal tissues. J Biol Chem 1957, 226:497-509.

21. Bligh EG, Dyer WJ: A rapid method of total lipid extraction and purification. Can J Biochem Physiol 1959, 37:911-917.

22. Hara A, Radin N: Lipid extraction of tissues with low-toxicity solvent. Anal Biochem 1978, 90(1):420-426

23. AOAC (Association of Official Analytical Chemists): Animal feed. Official Methods of Analysis; Arlington, 161995.

24. Parrish CC: Dissolved and particulate lipid classes in the aquatic environment. PhD thesis Dalhousie University, Halifax, Nova Scotia, Department of Oceanography; 1986.

25. Schettgen C: Bioakkumulation von Triclosan bei verschiedenen $\mathrm{pH}$ Werten des Wassers und der Pyrethroide Cyfluthrin, Cypermethrin, Deltamethrin und Permethrin. PhD thesis Universität Oldenburg; 2000.

26. Merck E: Gesamtlipide. I. Photometrische Bestimmung. In Klinisches Labor. Edited by: Merck E. Darmstadt, 12. Aufl; 1974:247-249.
27. Fox K, Zauke GP, Butte W: Kinetics of bioconcentration and clearance of 28 polychlorinated biphenyl congeners in zebrafish (Brachydanio rerio). Ecotox Environ Saf 1994, 28(1):99-109.

28. Yakata N, Sudo $\mathrm{Y}$, Tadokoro H: Influence of dispersants on bioconcentration factors of seven organic compounds with different lipophilicities and structures. Chemosphere 2006, 64(11):1885-1891.

29. Min KJ, Cha CG: Determination of the bioconcentration of phosphamidon and profenofos in zebrafish (Brachydanio rerio). Bull Environ Contam Toxicol 2000, 65(5):611-617.

30. Seo JS, Liu KH, Chung KH, Shin JS, Kim JH: Bioconcentration and depuration of Pyribenzoxim in common carp (Cyprinus carpio). Bull Environ Contam Toxicol 2002, 68(5):617-622.

31. Satyanarayan S, Ramakant R: Bioaccumulation kinetics and bioconcentration factor of chlorinated pesticides in tissues of Puntius ticto (Ham.). J Environ Sci Health 2004, B39(2):321-332.

32. Springer TA, Guiney PD, Krueger HO, Jaber MJ: Assessment of an approach to estimate aquatic bioconcentration factors using reduced sampling. Environ Toxicol Chem 2008, 27(11):2271-2280

33. De Boer J, Smedes F, Wells D, Allan A: Report on the Quash interlaboratory study on the determination of total-lipid in fish and shellfish. Round 1 SBT-2. Exercise 1000, 1999, EU, Standards, Measurement and Testing Programme.

34. Manirakiza P, Covaci A, Schepens P: Comparative study on total lipid determination using Soxhlet, Roese-Gottlieb, Bligh and Dyer, and modified Bligh and Dyer extraction methods. J Food Comp Anal 2001, 14:93-100

35. Quasimeme. [http://www.quasimeme.org]

36. Darwish DS, van de Voort FR, Smith JP: Proximate analysis of fish tissue by mid-infrared transmission spectroscopy. Can J Fish Aquatic Sci 1989, 46:644-649.

37. Mathias JA, Williams PC, Sobering DC: The determination of lipid and protein in freshwater fish using near-infrared reflectance spectroscopy. Aquaculture 1987, 61:303-311

38. Geyer HJ, Scheunert I, Brueggemann R, Matthies M, Steinberg CEW, Zitko V, Kettrup A, Garrison W: The relevance of aquatic organisms' lipid content to the toxicity of lipophilic chemicals: toxicity of lindane to different fish species. Ecotox Environ Saf 1994, 28:53-70.

39. Galassi S, Calamari D: Toxicokinetics of 1,2,3 and 1,2,4 trichlorbenzenes in early life stages of Salmo gairdneri. Chemosphere 1983, 12(11/ 12):1599-1603

40. Oliver BG, Niimi AJ: Bioconcentration of chlorobenzenes from water by rainbow trout: correlations with partition coefficients and environmental residues. Environ Sci Technol 1983, 17:287-291.

41. Pedersen F, Tyle H, Niemelä JR, Guttmann B, Lander L, Wedebrand A: Environmental Hazard Classification - Data Collection and Interpretation Guide. 2 edition. Copenhagen: The Nordic Council of Ministries; 1995.

42. Tolls J, Haller M, Labee E, Verweij M, Sijm DTHM: Experimental determination of bioconcentration of the nonionic surfactant alcohol ethoxylate. Environ Toxicol Chem 2000, 19:646-653.

43. ECHA, REACH TGD (R.7.10.4): Evaluation of available information on aquatic bioaccumulation. In Guidance for the Implementation of REACH: Guidance on Information Requirements and Chemical Safety Assessment. Volume 6. Helsinki; 2008.

44. Chefurka W, Gnidec EPP: Binding of $\left[{ }^{14} \mathrm{C}\right]$ DDT by submitochondrial particles. Comp Biochem Physiol C 1987, 88(1):213-217.

45. Roche $\mathrm{H}$, Buet $\mathrm{A}$, Jonot $\mathrm{O}$, Ramade $\mathrm{F}$ : Organochlorine residues in European eel (Anguilla anguilla), crucian carp (Carassius carassius) and catfish (Ictalurus nebulosus) from Vaccarès lagoon (French National Nature Reserve of Camargue) - effects on some physiological parameters. Aquat Toxicol 2000, 48(4):443-459

46. Wu WZ, Schramm KW, Xu Y, Kettrup A: Accumulation and partitioning of polychlorinated dibenzo-p-dioxins and dibenzonfurans (PCDD/F) in the muscle and liver of fish. Chemosphere 2001, 43(4-7):633-641.

47. Gunkel G, Streit B: Mechanisms of bioaccumulation of a herbicide (atrazine, s-triazine) in a freshwater mollusc (Ancylus fluviatilis müll.) and a fish (Coregonus fera jurine). Water Res 1980, 14:1574-1584.

48. Jabber SA, Khan YS, Rahman MS: Levels of organochlorine pesticides in some organs of the Ganges perch, Lates calcifer, from the GangesBrahmaputra-Meghna Estuary, Bangladesh. Mar Pollut Bull 2001, 42(12):1291-1296. 
49. Storelli MM, Marcotrigiano GO: Persistent organochlorine residues and toxic evaluation of polychlorinated biphenyls in sharks from the Mediterranean Sea (Italy). Mar Pollut Bull 2001, 42(12):1323-1329.

50. Pääkkönen JP, Rantalainen AL, Karels A, Nikkilä A, Karjalainen J: Bioaccumulation of PCBs in burbot (Lota lota) after delivery in natural food. Arch Environ Contam Toxicol 2005, 49(2):223-231.

51. Zhou R, Zhu L, Kong Q: Persistent chlorinated pesticides in fish species from Qiantang River in East China. Chemosphere 2007, 68(5):838-847.

52. Blanes MA, Serrano R, López FJ: Seasonal trends and tissue distribution of organochlorine pollutants in wild and farmed Gilthead Sea bream (Sparus aurata) from the Western Mediterranean Sea and their relationship with environmental and biological factors. Arch Environ Contam Toxicol 2009, 57(1):133-144.

53. Serrano R, Barreda M, Blanes MA: Investigating the presence of organochlorine pesticides and polychlorinated biphenyls in wild and farmed gilthead sea bream (Sparus aurata) from the Western Mediterranean Sea. Mar Pollut Bull 2008, 56(5):963-972.

doi:10.1186/2190-4715-24-13

Cite this article as: Schlechtriem et al.: Determination of lipid content in fish samples from bioaccumulation studies: contributions to the revision of guideline OECD 305. Environmental Sciences Europe 2012 24:13.

\section{Submit your manuscript to a SpringerOpen ${ }^{\mathcal{O}}$ journal and benefit from:}

- Convenient online submission

- Rigorous peer review

- Immediate publication on acceptance

- Open access: articles freely available online

- High visibility within the field

- Retaining the copyright to your article

Submit your next manuscript at $\gg$ springeropen.com 